\title{
Correlation between Breakfast Tryptophan Content and Morningness- Eveningness in Japanese Infants and Students Aged 0-15 yrs
}

\author{
Tetsuo Harada, Masaaki Hirotani, Mari Maeda, Hiromi Nomura and Hitomi Takeuchi \\ Laboratory of Environmental Physiology, Faculty of Education, Kochi University
}

\begin{abstract}
Tryptophan can be metabolized via 5hydroxytryptamine $=$ serotonin to melatonin by a series of 4 enzymes in pineal body. Lack of serotonin in body fluid in the brain during daytime can lead to several psychiatric disorders, while shortage of plasma-melatonin at night can be related to sleep disorders. The Morningness-Eveningness (M-E) questionnaire and the original questionnaire including questions on sleep habits, mental symptoms, and contents of meals were administered to 1055 infants aged 0-6yrs, 751 students attending an elementary school, and 473 students attending junior high school in Kochi City $\left(33^{\circ} \mathrm{N}\right)$. The index of tryptophan taken at breakfast (Trp-Index) was calculated as tryptophan amount per one meal based on the tryptophan included in each $100 \mathrm{~g}$ of the foods and a standard amount of food per one meal. A significant positive-correlation between M-E scores and Trp-Index was not shown by relatively older students, aged 9-15 yrs (Pearson's test, $r=0.044-0.123$, $p=0.071-0.505$ ), whereas a significant positive correlation was shown by infants and young elementary school students aged $0-8$ yrs $(r=0.180,0.258, p<0.001)$. The more frequently the infants had difficulty falling asleep at bedtime and waking up in the morning, the less the Trp-Indices taken at breakfast were (Kruskall-Wallis-test, $p=0.027$ for difficulty falling asleep; $p=0.008$ for difficulty waking up). The more frequently infants became angry even by a little trigger, or depressed, the lower (more evening-typed) the M-E scores were (Kruskal-Wallis test: $p \leq 0.001)$. Tryptophan ingested at breakfast is very important for children to keep a morning-type diurnal rhythm, high quality of sleep, and indirectly good mental health, presumably, through the metabolism of tryptophan to serotonin in daytime and further to melatonin at night. $J$ Physiol Anthropol 26(2): 201-207, $2007 \mathrm{http}: / /$ www.jstage.jst.go.jp/ browse/jpa2

[DOI: 10.2114/jpa2.26.201]
\end{abstract}

Keywords: Morningness-Eveningness, breakfast, tryptohphan content, mental health, Japanese children and adolescents, $0-15 \mathrm{yrs}$

\section{Introduction}

Tryptophan is one of the essential amino acids which should be absorbed exclusively from meals. It is metabolized via 5hydroxytryptamine $=$ serotonin to melatonin by a series of 4 enzymes in pineal body (Moore et al., 2000; Zheng et al., 2004). Exposure to sunlight in the daytime seems to trigger the synthesis of serotonin in pineal (Rosenthal et al., 1997). Aggression, anxiety/aggression-driven depression, impulsive behavior, and suicidal attempts may be induced by lower serotonin (5-HA) or serotonin disturbance (Linnoila et al., 1993; Van Praag, 2001).

External melatonin treatment is effective for the phase advance of the sleep-wake cycle of DSPS (delayed sleep phase syndrome) patients (Turek and Czeisler, 1999). High plasma melatonin levels at night can be hypothesized to play an important role in sleep onset and sleep quality (Turek and Czeisler, 1999). In infants, the plasma melatonin level at night is several times as high as that in adolescents and adults (Waldhauser et al., 1988). Is the amount of tryptophan taken in at breakfast related to sleep habitats and the circadian typology shown by the Morningness-Eveningness score, especially in infants?

There have been several studies on the relationship between $\mathrm{M}-\mathrm{E}$ preference and selected psychological variables. Levy (1985) found evening types more pessimistic than morning types. Moreover, there were negative correlation between the Horne and Östberg questionnaire score and the responses on the 3 depression scales of the BDI (Beck Depression Inventory), GDS-SF (Geriatric Depression Scale-Short Form, 15-item), and CESD (Center for Epidemiological Studies Depression Scale) (Chelminsky et al., 1999). Tankova et al. (1994), however, in their review of studies that examined the relationship between circadian typology and other individual difference variables, concluded that neuroticism and psychoticism are not associated with performance on "morningness-eveningness" scales. However, epidemiological studies by Harada (2004) showed that evening-type students had lower mood, higher irritation, and more easily triggered anger than morning-type ones. One causal factor for evening- 
Table 1 A version for infants of the Morningness-Eveningness questionnaire Torsvall \& Åkerstedt (1980) originally constructed.

1. When would your child prefer to rise (provided your child has a full day's play- $8 \mathrm{~h}$ ) if your child was totally free to arrange his (her) time ? (4) before 06:30, (3) 06:30-07:29, (2) 07:30-08:29, (1) 08:30 or later

2. When would your child prefer to go to bed (provided your child has a full day's play-8h) if your child was totally free to his (her) time ?

(4) before $21: 00$, , (3) 21:00-21:59, (2) 22:00-22:59, (1) 23:00 or later

3. If he (she) always had to go to bed at 21:00, what does your child think it would be like to fall asleep then ?

(4) easy — would fall asleep practically at once,

(3) rather easy-would like awake for a short while,

(2) rather difficult—would like awake for some time,

(1) very difficult - would like awake for a long time

4. If he (she) always had to rise at 06:00, what does your child think it would be like to get up then ?

(4) easy-no problem at all

(3) a little unpleasant but not a great problem

(2) rather difficult and unpleasant

(1) very difficult and unpleasant

5. When does your child usually begin to feel the first signs of tiredness and need for sleep ?

(4) before 21:00, (3) 21:00-21:59, (2) 22:00-22:59, (1) 23:00 or later

6. How long a time does it usually take before your child "recovers his (her) faculties" in the morning after rising from a night's sleep ?

(4) 1-10 min., (3) 11-20 min, (2) 21-40 min, (1) more than $40 \mathrm{~min}$

7. Please, indicate to what extent your child is a morining or evening active individual.

(4) pronounced morning active (morning alert and evening tired)

(3) to some extent morning active

(2) to some extent evening active (morning tired and evening alert)

(1) pronounced evening active

type students to have worse mental health is hypothesized to be inner de-synchronization of the main and slave clocks (Harada, 2004; Kripke et al., 1978). Another cause of the worse mental health shown by evening-type students can be supposed to be the lower level of serotonin in the brain in the daytime. The low level of serotonin may be due to the low amount of intake of tryptophan at breakfast by evening-typed students. The rapid tryptophan depletion technique (RTD), which is accomplished by consuming a tryptophan-free amino acid drink, was reported to induce lower levels of serotonin and melatonin followed by increased depression in several psychiatric patients (Moore et al., 2000). For example, RTD induced a depressive relapse in 14 of 21 inpatients hospitalized for major depressive disorder who had responded well to antidepressant therapy (Delgado et al., 1990). This study aims to answer the following questions from the epidemiological point of view.

1. Is the amount of tryptophan intake at breakfast related to sleep habits and circadian typology shown by the Morningness-Eveningness score, especially in infants?

2. Is the amount of tryptophan intake at breakfast related to the mental health of Japanese infants, pupils, and adolescents?

\section{Materials and Methods}

\section{Morningness-Eveningness questionnaire and original questionnaire}

A modified version for infants (Table 1) based on the Japanese version (Takeuchi et al., 2001a) for students of a Morningness-Eveningness Questionnaire (MEQ) was used in this study. The questionnaire was translated from the English version and slightly modified for students (Takeuchi et al., 2001a) based on the MEQ that Torsvall and Åkerstedt (1980) originally constructed for general workers. Three of seven questions included in the MEQ pertain to sleep onset timing in the evening, three to sleep offset timing in the morning, and one to peak timing of activity during the daytime. Each question allows for choice, from evening- to morning-type (scored from 1 to 4 ). The $\mathrm{M}-\mathrm{E}$ score is the summation of the seven answers. The minimal possible score (extreme eveningtype) is 7 , and the maximal possible score (extreme morningtype) is 28. The common MEQ questionnaire was used to compare the Morningness-Eveningness typology among ages $0-15$ yrs. Infants within 6 months of birth were excluded from this study, because parents cannot answer the questions, due to specific sleep and feeding habits in this early stage (Korte et al., 2001). An original questionnaire was also used for the study, including the two questions on mental symptoms shown in Table 2, and original questions on sleep habits which Harada et al. (1998) originally constructed and were used in several papers (Takeuchi et al., 2001a; Takeuchi et al., 2001b; Harada et al., 2002; Takeuchi et al., 2003; Harada et al., 2004; Shinomiya et al., 2004). The MEQ and the original questionnaire were administered to 1055 infants aged 0-6yrs, 751 students attending an elementary school, and 473 students attending a junior high school located in Kochi City $\left(33^{\circ} \mathrm{N}\right)$. Parents, 93\% of whom were mothers, answered, instead, the questionnaire for their children aged 0-8 yrs [740 infants and 195 students of the first and second grades). 440 of the 480 elementary school students in the third to sixth grades and 445 of the 480 junior high students answered the questionnaire. All 740 infants were attending one of 9 kindergartens which were constructed by the government of Kochi City. The sex ratio 
Table 2 Average tryptophan contents in foods and average gram of foods-intake per one meal to calculate the index of tryptophan.

\begin{tabular}{lccc}
\hline \multicolumn{1}{c}{ Foods } & $\begin{array}{c}\text { Tryptophan }(\mathrm{mg}) \\
\text { /100 g }\end{array}$ & $\begin{array}{c}\text { Average food } \\
\text { intake (g) }\end{array}$ & $\begin{array}{c}\text { Try.-Index } \\
(\mathrm{mg})\end{array}$ \\
\hline Eggs & 180 & 50 & 90 \\
Meats $\quad$ (beef, pork, chicken) & & 100 & 205 \\
Milk & 45 & 100 & 45 \\
Bread or rice & 105 & 100 & 105 \\
Vegetable & 20 & 100 & 20 \\
Fruit juice & 2 & 100 & 2 \\
"Natto" & 245 & 40 & 98 \\
Seaweed & 150 & 10 & 15 \\
Non-dry fish & 215 & 100 & 215 \\
Dry fish & 530 & 10 & 53 \\
Coffee or tea & 30 & 100 & 30 \\
"Miso" & 125 & 20 & 25 \\
\hline
\end{tabular}

(DATAbase on functional foods factors Tokyo Agriculture University Lab of Public Nutrition Health Home Page, 2004)

was almost half and half in all grades of participants aged 0-15 yrs. Answers to the questionnaire were collected in June-November, 2004.

\section{Statistical analysis}

Data were statistically analyzed using Pearson's correlation test, the Wilcoxon test, the Mann-Whitney U-test, the Kruskal-Wallis test and ANOVA, using SPSS statistical analyzing software (version 11.5) for personal computer. M-E scores were expressed as means plus or minus the standard deviation $($ Mean $\pm \mathrm{SD})$.

\section{Procedure}

The study followed the guidelines established by the journal Chronobiology International for the conduct of research on human subjects (Touitou et al., 2004). We carefully explained the concepts and purposes of this study in writing and orally: "Questionnaires are completely unregistered and answers to them will be used only for academic purposes," to kindergarten nurses and the parents of the infants. This study was permitted by the kindergarten nurses' committees of nine kindergartens and the elementary and junior high schools which carried out an ethical inspection of the contents of the questionnaire. After the explanation, all the parents of the participants completely agreed with our proposal for epidemiological work. The survey was administered at home for younger children, aged $0-8$ yrs (infants and students in the first and second grades), and in the classrooms of the schools for older students (students in the third to sixth grades of elementary school and junior high students).

\section{Question on the contents of breakfast}

"Please mark all the foods taken by your child at a usual breakfast from the following":

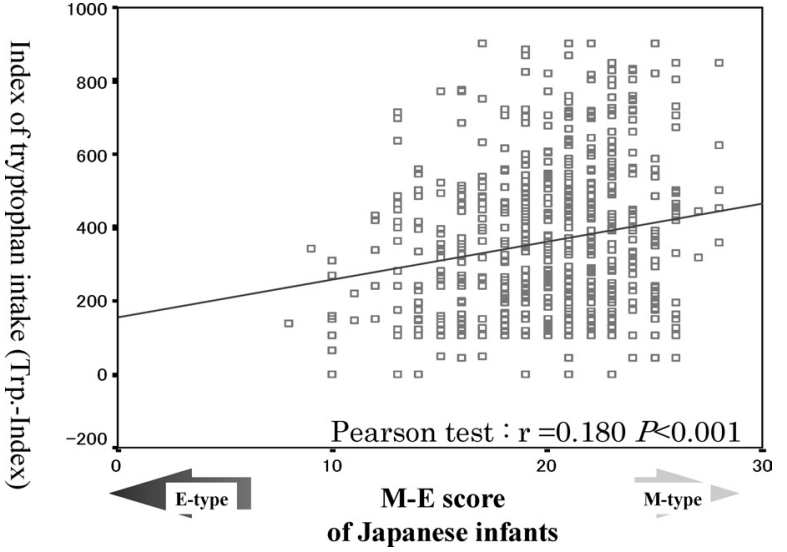

Fig. 1 Relationship between amount of tryptophan intake in breakfast and $\mathrm{M}-\mathrm{E}$ score in Japanese infants.

(1) eggs

(2) meats [including ham and bacon]

(3) milk

(4) vegetables

(5) boiled rice

(6) bread

(7) fruit juice

(8) fermented soybeans ("Natto")

The index of tryptophan (Trp-Index) taken from breakfast was calculated as the tryptophan amount per one meal based on the tryptophan included in each $100 \mathrm{~g}$ of the foods and a standard amount of food per one meal (Table 2) (Gomyo and Hasegawa, 1993).

\section{Results}

$M-E$ scores and breakfast tryptophan content by infants and students aged 0-15 yrs

The average and SD of the M-E scores were 20.04 \pm 3.58 (657 infants aged $0-6 \mathrm{yrs}$ ), 19.79 \pm 3.48 (211 students in the first and second grades of elementary school, 6-8 yrs), $17.74 \pm 3.83$ (214 students in the third and fourth grades, 8-10 yrs), 16.42 \pm 3.98 (226 students in the fifth and sixth grades, 10-12 yrs), $15.33 \pm 3.79$ (419 junior high students, 12-15 yrs). A significant positive-correlation between M-E scores and the Trp-Index was not shown by relatively older students, aged 9-15yrs, but was shown by infants and young elementary school students aged 0-8yrs (Pearson's test: $r=0.180$, $p<0.001$ for infants; $r=0.258, p<0.001$ for students in first and second grades; $r=0.123, p=0.071$ for students in the third and fourth grades; $r=0.044, p=0.505$ for the fifth and sixth grades; $r=0.081, p=0.098$ for junior high students) (Figs. 1, 2).

Breakfast tryptophan content and sleep quality by infants aged 0-6 yrs

The Trp-Index of the infants who had a very short sleep- 

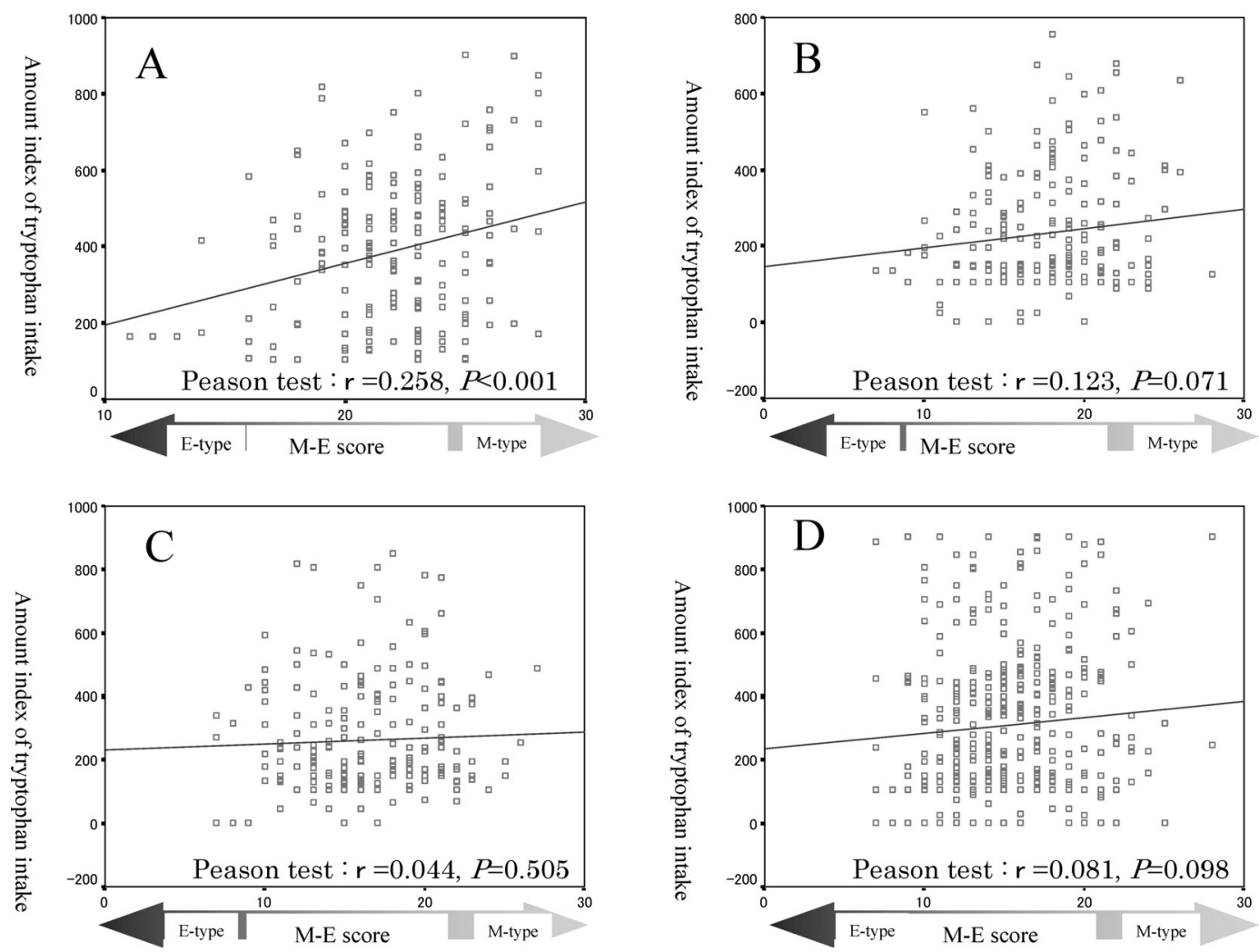

Fig. 2 Correlative analysis between amount of tryptophan intake in breakfast and M-E score in Japanese students in first and second grades (A), third and fourth grades (B), and fifth and sixth grades (C) of elementary school, and junior high school students (D).

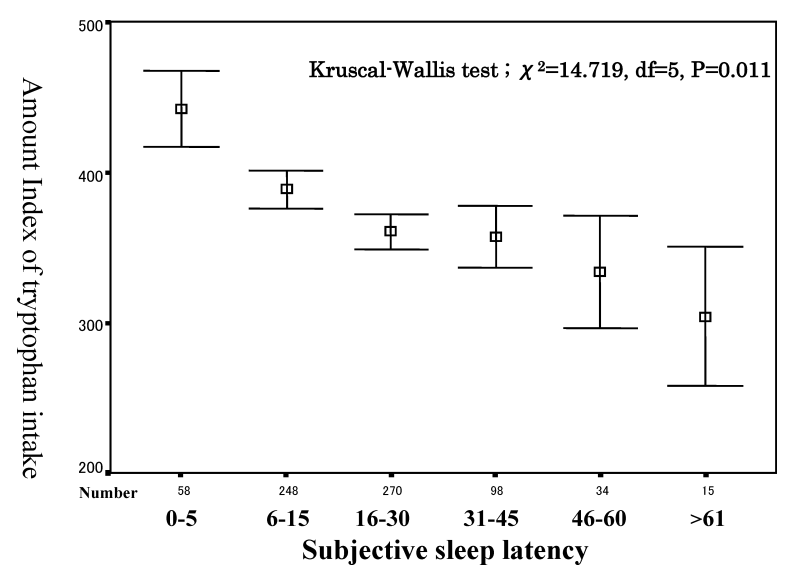

Fig. 3 Relationship between tryptophan intake in breakfast and subjective sleep latency in Japanese infants aged 0-6 yrs.

latency of less than $5 \mathrm{~min}$ was $440 \mathrm{mg}$ and significantly higher than that $(302 \mathrm{mg})$ of those who showed a sleep-latency of more than $60 \mathrm{~min}$ (Kruskall-Wallis test ; $\chi^{2}=14.719, d f=5$, $p=0.011$ ) (Fig. 3). The more frequently the infants had difficulty falling asleep at bedtime and difficulty waking up in the morning, the less their Trp-Indices at breakfast were (Kruskall-Wallis-test: $\chi^{2}=10.922, d f=4, p=0.027$, falling asleep; $\chi^{2}=13.740, d f=4, p=0.008$, waking up) (Figs. 4, 5).

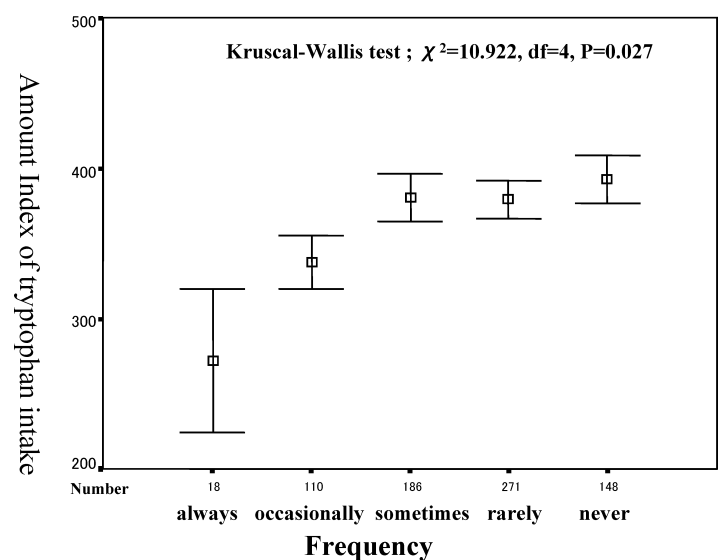

Fig. 4 Relationship between tryptophan intake in breakfast and frequency to feel difficulty to fall asleep in Japanese infants aged 0-6 yrs.

Relationship between mental symptoms and Morningness-Eveningness preference or breakfast tryptophan content of infants aged 0-6yrs

No significant differences in Trp-index were shown among infants feeling anger or depression with different frequencies (Kruskal-Wallis test: $\chi^{2}$-value $=4.38, d f=3, p=0.224$ on anger, $\chi^{2}$-value $=3.80, d f=3, p=0.284$ on depression). However, the more frequently infants became angry even by a little trigger, 


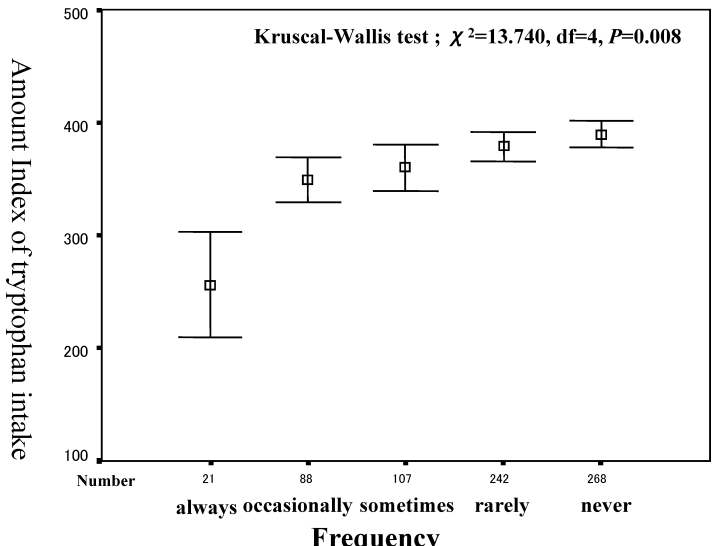

Fig. 5 Relationship between tryptophan intake in breakfast and frequency to feel difficulty to be awakened in Japanese infants.

or depressed, the lower (more evening-typed) the Morningness-Eveningness scores were (Kruskal-Wallis test: $\chi^{2}$-value $=18.43, d f=3, p<0.001$ on anger, $\chi^{2}$-value $=15.72$, $d f=3, p=0.001$ on depression) (Figs. 6, 7).

\section{Discussion}

Morning tryptophan intake affecting sleep habit and circadian typology

Among 20 kinds of amino acids, only tryptophan can be metabolized finally to melatonin, which is the key substance to trigger sleep. The amount of tryptophan digested at breakfast may affect the synthesized amount of serotonin in the daytime, especially in the morning. The amount of serotonin can decide, in turn, the amount of synthesized melatonin at night. This serotonin synthesis is hypothesized to occur mainly in the morning hours, because the amount of tryptophan at supper has neither significant effects on M-E scores (Pearson's correlation test: $r=0.191, n=591, p<0.001$ in breakfast; $r=0.100, n=600, p=0.067$ in supper) nor an effect on sleep habit in another study on Japanese infants performed in 2005 (Harada et al., unpublished).

Tryptophan intake at breakfast is effective for the onset and offset of sleep in infants (Figs. 3, 4, 5). A high amount of melatonin synthesized from tryptophan taken in the morning may produce good sleep habits. Tryptophan taken in at supper may be used not for serotonin synthesis the next morning but for the general synthesis of several proteins. A high amount of serotonin in the morning and the subsequent high amount of melatonin in the evening can be efficient zeitgebers to circadian oscillators, making the infants more morning-typed. The amount of plasma melatonin at night derived from tryptophan may affect sleep quality directly and/or through the phase advance of the so-called "slave-oscillator"driving sleepwake cycle (Aschoff et al., 1967). The amount of daytime serotonin may be related to SCN circadian phase control by daytime light in humans (Pickart and Rea, 1997).

Age-specific aspects are possible in the intensity of the

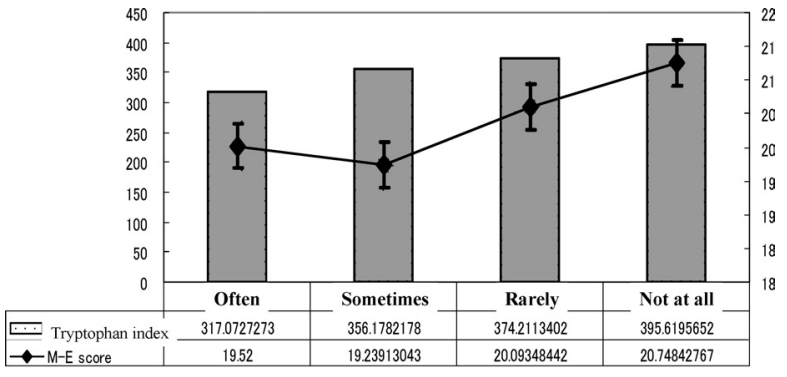

Frequency to becoming angry even by a little trigger

Fig. 6 Relationship of frequency to be angry even by a little trigger to Morningness-Eveningness preference and amount of tryptophan to be taken in breakfast of Japanese infants aged 0-6 yrs.

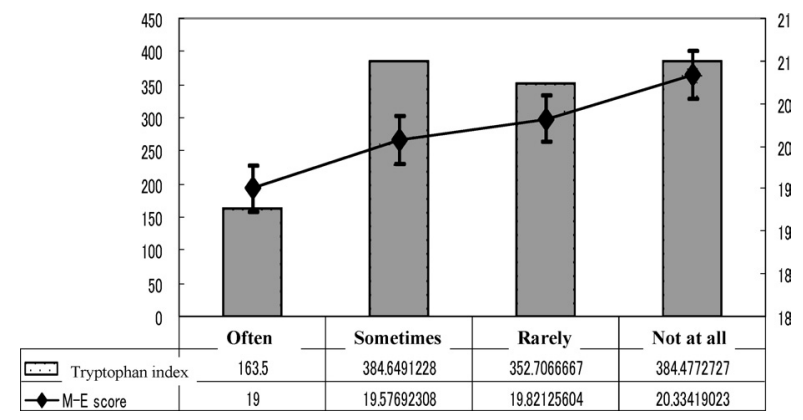

Fig. 7 Relationship of frequency to be depressed to MorningnessEveningness preference and amount of tryptophan to be taken in breakfast of Japanese infants aged 0-6 yrs.

morning-type-driven effects of tryptophan taken in at breakfast. A significant positive correlation between $\mathrm{M}-\mathrm{E}$ scores and the amount of tryptophan taken in at breakfast was not shown for elementary school children in the third to sixth grades and adolescents aged $8-15 \mathrm{yrs}$, but it was shown for infants aged 0-6yrs and elementary school children aged 6-8 yrs (Fig. 2). Plasma melatonin concentration at night is very high in the infants and young children aged $1-7 \mathrm{yrs}$, the value being 5 to 8 times that in adults (Waldhauser et al., 1988). A high blood concentration of serotonin in the brain in the morning and, in turn, high concentration of melatonin in the evening is necessary for infants and young children.

Therefore, a low intake of tryptophan taken at breakfast may easily induce disorders in sleep quality and the circadian typology of infants and young children aged 1-8 yrs.

\section{Breakfast tryptophan intake and mental symptoms}

Based on the results of this study, tryptophan intake at breakfast has no direct effect on mental symptoms such as depression and anger in infants. However, there is some potential for indirect linkage of a permanent lack of tryptophan intake to the induction of low mental symptoms via the shift to the evening typology.

A shortage of catecholamines, adrenaline, noradrenaline, and dopamine is known as neuroamines to induce affective disorders (Ikuta, 2005). Phenylalanine and tyrosine taken at 
mealtimes as a source of catecholamines may promote the improvement of mental health of children. The analysis of this remains to be done in the future.

In conclusion, tryptophan absorbed at breakfast is very important for children to keep to a morning-type diurnal rhythm and a high quality of sleep, presumably through the metabolism of tryptophan to serotonin in the daytime and further to melatonin at night.

Acknowledgments This study was financially supported by a Foundation Grant of the President of Kochi University for the Promotion of Education and Research (2000-2003), the Meiji-Yasuda Life Welfare Foundation (2004-2005), and Research Foundation on "Natto" (2006).

\section{References}

Aschoff J, Gerecke U, Wever R (1967) Desynchronization of human circadian rhythms. Jpn J Physiol 17: 450-457

Chelminski I, Ferraro FR, Petros T., Plaud, JJ (1999) An analysis of the "evening-morningness" dimension in "depressive" college students. J Affect Dis 52: 19-29

Delgado PL, Charney DS, Price LH, Aghajanian GK, Landis $\mathrm{H}$, Heninger GR (1990) Serotonin function and the mechanism of antidepressant action: Reversal of antidepressant-induced remission by rapid depletion of plasma tryptophan. Arch Gen Psychiatry 47: 411-418.

Gomyo N, Hasegawa K (1993) Tables on the components of amino acids and fatty acids which are responsible for the value of protein and oil \& fat. Kagawa Nutrition University Publishing Division, Tokyo, 292.

Harada T, Morikuni M, Yoshii S, Yamashita Y, Takeuchi H (2002) Usage of a mobile phone in the evening or at night makes Japanese students evening-typed and night sleep uncomfortable. Sleep and Hypnosis 4: 150-154

Harada T (2004) Evening-typed diurnal rhythm in Japanese children and their mental health. Journal of Child Health 63: 202-209 [in Japanese].

Harada T, Kadowaki A, Shinomiya H, Takeuchi H (2004) Relationship between watching late night $\mathrm{TV}$ and morningness-eveningness of 18-22-years old Japanese students. Sleep and Biological Rhythms 2: 97-98

Harada T, Inoue M, Takeuchi H, Watanabe N, Hamada M, Kadota G, YamashitaY (1998) Study on diurnal rhythms in the life of Japanese university, junior high and elementary school students including morningness-eveningness preference. Bulletin of the Faculty of Education, Kochi University Series 1 56: 1-91 [in Japanese]

Ikuta S (2005) Mental disorders can be well treated by ordinary meals. Series of New PHP Books, No. 336, PHP Institute, Tokyo, Japan, 222 [in Japanese]

Korte J, Wulff K, Oppe C, Siegmund R (2001) Ultradian and circadian rhythms of preterm neonates compared to fullterm neonates using actigraphic monitoring. Chronobiology International 18: 697-708.
Kripke DF, Mullaney DJ, Atkinson M et al. (1978) Circadian rhythm disorders in manic-depressives. Biol Psychiatry 13: 335-351

Levy, DA (1985) Optimism and pessimism: relationship to circadian rhythms. Psych Rep 57: 1123-1126

Linnoila M, Higley D, Nielsen D, Andreason P, Suomi S, Goldman D, Virkkunen M (1993) Serotonin and Impulse control: From clinic to clone. European Neuropsychopharmacology 3: 161

Moore P, Landolt HP, Seifritz E, Clark C, Bhatti T, Kelsoe J, Rapaport M, Gillin C (2000) Clinical and physiological consequences of rapid tryptophan depletion. Neuropsychopharmacology 23: 601-622

Pickard GE, Rea MA (1997) Serotonergic innervation of the hypothalamic suprachiasmatic nucleus and photic regulation of circadian rhythms. 89: 513-523

Rosenthal N, Schwartz P, Tumer E, Naim S, Matthews J, Hardin T, Bamett R, Wehr T (1997) The psychobiology of $\mathrm{SAD}$ and the mechanism of action of light therapy. Biol Psychiatry 42: 57S

Shinomiya H, Takeuchi H, Martoni M, Natale V, Harada T (2004) Comparative study on circadian typology of Japanese and Italian students aged 12-18 years. Sleep and Biological Rhythms 2: 93-95

Takeuchi H, Inoue M, Watanabe N, Yamashita Y, Hamada M, Kadota G, Harada T (2001a) Parental enforcement of bedtime during childhood results in Japanese junior high school students preferring morningness to eveningness. Chronobiology International 18: 823-829

Takeuchi H, Hino N, Iwanaga A, Hino N, Matsuoka A, Harada $\mathrm{T}$ (2001b) Light conditions during sleep period and sleeprelated lifestyle in Japanese students. Psychiatry and Clinical Neurosciences 55: 221-222

Takeuchi H, Oishi T, Harada T (2003) Morningnesseveningness preference, and mental and physical symptoms during the menstrual cycle of Japanse junior high school students. Sleep and Biological Rhythms 1: 245-247

Tankova I, Adan A, Buela-Casal G (1994) Circadian typology and individual differences. A review. Person Indvid Diff 16: 671-684

Torsval MD, Åkerstedt TA (1980) Diurnal type scale: construction, consistency and validation in shift work. Scand J Work Environ Health 6: 283-290

Touitou Y, Portaluppi, F, Smolensky, MH, Rensing, L (2004). Ethical principles and standards for the conduct of human and animal biological rhythm research. Chronobiol Int 21:161-170.

Turek FW, Czeisler CA (1999) Role of melatonin in the regulation of sleep. In (Turek, FW and Zee PC eds.) Regulation of Sleep and Circadian Rhythms 1999. Marcel Dekker, Inc., New York/Basel, 181-195

Van Praag, HM (2001) Anxiety-/Aggression-driven depression: A paradigm of functionalization and verticalization of psychiatric diagnosis. Prog NeuroPsychopharmacol \& Biol Psychiat 25: 893-924 
Waldhauser F, Kovacs J, Reiter E (1988) Age-related changes in melatonin levels in humans and its potential consequences for sleep disorders. Experimental Gerontology 33: $759-772$

Zheng X, Beaulieu JM, Sotnikova TD, Gainetdinov RR, Caron MG (2004) Tryptophan hydroxylase-2 controls brain serotonin synthesis. Science 305: 217

This article was presented at the 8th International Congress of Physiological Anthropology, 2006 (ICPA 2006), in Kamakura,
Japan

Received: September 26, 2006

Accepted: December 15, 2006

Correspondence to: Tetsuo Harada, Laboratory of Environmental Physiology, Faculty of Education, Kochi University, 2-5-1 Akebonocho, Kochi 780-8520, Japan

Phone: +81-88-844-8410

Fax: +81-88-844-8410

e-mail: haratets@cc.kochi-u.ac.jp 